\title{
Inviting travelers to the smorgasbord of sustainable urban transport: evidence from a MaaS field trial
}

\author{
Helena Strömberg $^{1}$ (D) I. C. MariAnne Karlsson ${ }^{1}$ (D) Jana Sochor ${ }^{1,2}$ (D) \\ Published online: 2 November 2018 \\ (c) The Author(s) 2018
}

\begin{abstract}
A Mobility-as-a-Service (MaaS) concept, UbiGo, was implemented in Gothenburg, Sweden, and used for a 6-month period by 195 individuals in 83 households. Four participant subgroups were identified: Car shedders, Car accessors, Simplifiers, and Economizers. A qualitative analysis revealed that the subgroups had different reasons to join the service and different expectations of the change that would occur on the basis of the altered preconditions offered by the service. Previous car users reduced their use of private car and increased their use of public transport and active modes. Participants who did not have access to a privately-owned car but thought they needed one discovered that they managed well without. Other participants were reinforced in their existing behaviors but in ways they did not envisage, depending on which goals they had at the outset of the trial. Overall, the participants were also satisfied with the service, as well as with stated changes and nonchanges, even if this in some cases meant more planning. Based on the empirical findings it could be argued that a service approach, such as UbiGo, has the potential to reduce the need for private car ownership, and enable people to change their mode choices and travel patterns. The potential relies however on a number of specific features of the service of which flexibility and a need- rather than a mode-based approach are key features.
\end{abstract}

Keywords Mobility-as-a-Service (MaaS) - Travel behavior · Mode choice $\cdot$ Field operational test $\cdot$ Sustainable transport

A version of the content of this paper was presented at the 97th Annual Meeting of the Transportation Research Board, Washington, DC January 7-11, 2018.

Helena Strömberg

helena.stromberg@chalmers.se

1 Division Design \& Human Factors, Department of Industrial and Materials Science, Chalmers

University of Technology, SE-412 96 Gothenburg, Sweden

2 RISE Viktoria, Lindholmspiren 3A, SE-417 56 Gothenburg, Sweden 


\section{Introduction}

The transition to sustainable urban mobility is generally acknowledged as one of the major challenges for the future (Audenhove et al. 2014). To meet sustainability targets, a mix of technological improvement and behavioral change is commonly argued to be necessary (May 2013; Marsden et al. 2014; Lyons 2011). Development is not limited to only more efficient technology (e.g. more efficient and less carbon intensive vehicles), but also includes new ways of producing, delivering and consuming transport through integrated mobility solutions, such as the emerging concept of Mobility as a Service (MaaS).

$\mathrm{MaaS}$ is an organizational and technological approach to attract and enable people to give up their private car by providing a competitive service offer (Kamargianni et al. 2016). Although there is ongoing debate about what constitutes MaaS, central elements include: offering a service that focuses on the customer's/user's/traveler's transport needs; offering mobility and access rather than transport; and offering integration of transport services, information, booking, payment, etc. (Sochor et al. 2017). Building upon different types of integration, Sochor and colleagues (2017) propose a MaaS typology as a tool for facilitating comparisons of MaaS as well as for understanding potential effects. The typology suggests five levels of MaaS integration (0-4) where level 0 is no integration (e.g. separate services), level 1 integration of information (e.g. travel planners), level 2 integration of payment (e.g. SMILE or moovel), level 3 integration of the customer relationship and experience (e.g. UbiGo or MaaS Global), and level 4 integration of policy (no examples). At higher integration levels, for example at level 3, which is the focus of this paper, MaaS can offer an integrated multimodal mobility package as a competitive alternative to car, instead of focusing on promoting a single, alternative mode.

$\mathrm{MaaS}$ is predicted to contribute to sustainability by increased sharing of mobility resources, reducing the number of vehicles needed as well as simplifying multimodality through integration (Preston 2012; Karlsson et al. 2017). However, for MaaS to lead to a decrease in car ownership and use, travelers are still required to change behavior, which has been hard to bring about (Graham-Rowe et al. 2011). While previous behavior change interventions have mostly focused on informing and motivating individuals to change (Cairns et al. 2008; Brög 1998; Börjesson et al. 2012), MaaS takes a different approach. The expectation of MaaS is that by meeting the individual traveler's mobility needs in an easy-to-access, tailor-made service package, the travelers' ability to choose and combine the most appropriate transport options for their trips will improve, decreasing their need to own a car. In a recent stakeholder analysis, $80 \%$ of participants reported that they expected private car use to be significantly reduced due to MaaS (König et al. 2016). Based on such expectations, the European MaaS Alliance states that "MaaS has the potential to fundamentally change the behavior of people in and beyond cities, hence it is regarded as the biggest paradigm change in transport since affordable cars came into the market" (https:// maas-alliance.eu/).

However, empirical studies of the effects of MaaS on user behavior are scarce, as few implementations of MaaS have been made (as yet), let alone have been openly evaluated. Several pilots are underway, such as Whim in Helsinki and EU Horizon 2020 projects IMOVE and MaaS4EU which started mid-2017. UbiGo is still an exception, having been trialed and evaluated in a six-month Field Operational Test (FOT) in Gothenburg, Sweden.

Based on the insights gathered in that FOT, this paper aims to present analyses and discussions regarding who the (potential) MaaS customer is, their expectations, and their behavior. In particular, the paper examines the following questions: (a) What users does 
such a service (and value offering) attract? (b) For what reasons do users join such a service, and what are the users' expectations of the service and of themselves? and (c) How can such a service lead to (or hinder) behavioral change?

\section{The UbiGo service}

UbiGo was a service developed, implemented, tested, and evaluated within the Go:Smart project (http://closer.lindholmen.se/en/about-closer/gosmart) in 2013-2014. The context was Gothenburg, a city on the west coast of Sweden with a fairly well developed public transport (PT) system including buses, trams, ferries, as well as bicycle and carsharing services. UbiGo adopted a holistic view of mobility including multimodal integration and one-stop access to a full range of collective and active mobility services (Sochor et al. 2014). It offered transport services customized for each household, with a modifiable subscription comprising any combination of PT, taxi, car- and bicycle-sharing, and car rental, accessed and managed via a smartphone app. The credit for PT was in the form of daily tickets, and for car (rental or sharing), hours. Bicycle-sharing use over $30 \mathrm{~min}$ and taxi rides were invoiced at the end of the month. Credit could be topped up or rolled over.

\section{Method}

UbiGo was tested in a six-month FOT; a term which here refers to a test during which the participants were to use the new service as part of their everyday lives, ad lib and with no particular requests attached (apart from responding to three questionnaires). This meant for instance that participants became actual customers who paid for the service. The minimum household subscription level was $1200 \mathrm{SEK} /$ month in prepaid credit (approximately $€ 135 / \$ 185$ at the time of the trial). During the trial, participants were also given the possibility to set their car aside in care of the project with some economic compensation, mainly for depreciation. All in all, 20 households did this, 17 of which were single-vehicle households. Furthermore, the service was set up so as to function as a real up-and-running service with back-office functions including invoicing procedures and 24/7 customer service.

\section{Participants and recruitment}

The intended audience for the service was urban households judged to have sufficient access to the existing transport solutions (carsharing and PT in particular), and large enough travel needs for UbiGo to be economically competitive with their current solution. The 'household' could be comprised of any number of individuals including both adults and children, i.e. typically a family.

Participants were recruited using media, internet, social media, and targeted marketing in areas where the transport infrastructure was considered sufficient. The recruitment material targeted groups deemed to benefit from the service, that is households with a seldomused car, households considering buying a car, or households already using many of the included services and interested in an easier way to handle them.

The resulting UbiGo participant group consisted of 83 customer subscriptions covering 195 persons: 173 adults and 22 children (under 18). Table 1 provides a socio-demographic breakdown of the sample, and comparison with the 
Table 1 Socio-demographics of the UbiGo participants (with comparison to Gothenburg municipality)

\begin{tabular}{|c|c|c|}
\hline Demographic & $\begin{array}{l}\text { UbiGo ex-ante ques- } \\
\text { tionnaire } N=164\end{array}$ & $\begin{array}{l}\text { Gothenburg municipality } \\
\text { (kommun) } \mathrm{N}=548,190\end{array}$ \\
\hline \multicolumn{3}{|l|}{ Gender } \\
\hline Men & $51 \%(83)$ & $50 \%$ \\
\hline Women & $49 \%(81)$ & $50 \%$ \\
\hline \multicolumn{3}{|l|}{ Age } \\
\hline Young (19-29) & $28 \%(46)$ & $19 \%$ \\
\hline Middle (30-44) & $35 \%(58)$ & $23 \%$ \\
\hline Older (45-64) & $32 \%(53)$ & $23 \%$ \\
\hline \multicolumn{3}{|l|}{ Residence* } \\
\hline Apartment & $80 \%(132)$ & \\
\hline House & $20 \%(32)$ & \\
\hline \multicolumn{3}{|l|}{ Household type* } \\
\hline Single, no children & $9 \%(14)$ & $43 \%$ \\
\hline Couple, no children & $31 \%(51)$ & $20 \%$ \\
\hline With minors & $\begin{array}{l}29 \%(48) \\
16 \%: 3+\text { adults }(26) \\
15 \%: \text { Extended }(25)\end{array}$ & $24 \%$ \\
\hline Driver's license & $88 \%(144)$ & $85 \%$ (region) \\
\hline \multicolumn{3}{|l|}{ Car ownership per household* } \\
\hline No car & $52 \%$ & $55 \%$ \\
\hline 1 & $36 \%$ & $36 \%$ \\
\hline $2+$ & $12 \%$ & $9 \%$ \\
\hline \multicolumn{3}{|c|}{ Daily personal access to a car (\% of licensees) } \\
\hline Yes & $41 \%$ (59 of 144$)$ & - \\
\hline No & $59 \%(85$ of 144$)$ & - \\
\hline \multicolumn{3}{|c|}{ Household membership in carsharing scheme* } \\
\hline Yes & $30 \%(50)$ & - \\
\hline No & $70 \%(114)$ & - \\
\hline Public transit card & $88 \%$ & $80 \%$ \\
\hline \multicolumn{3}{|l|}{ Daily use of Internet and apps } \\
\hline Internet (computer) & $88.4 \%(145)$ & - \\
\hline Internet (tablet/smartphone) & $90.9 \%(149)$ & - \\
\hline Apps (tablet/smartphone) & $90.2 \%(148)$ & - \\
\hline \multicolumn{3}{|l|}{ Residential location } \\
\hline City center & $42 \%$ & $23 \%$ \\
\hline Southwest & $14 \%$ & $20 \%$ \\
\hline Southeast & $13 \%$ & $11 \%$ \\
\hline Northeast & $1 \%$ & $18 \%$ \\
\hline North (Hisingen) & $20 \%$ & $28 \%$ \\
\hline Other & $9 \%$ & - \\
\hline \multicolumn{3}{|l|}{ Occupation } \\
\hline Employed & $80 \%(131)$ & $59 \%$ \\
\hline Retired & $1 \%(2)$ & $19 \%$ \\
\hline Student & $11 \%(18)$ & $15 \%$ \\
\hline Other & $8 \%(13)$ & $7 \%$ \\
\hline
\end{tabular}


Table 1 (continued)

\begin{tabular}{|c|c|c|}
\hline Demographic & $\begin{array}{l}\text { UbiGo ex-ante ques- } \\
\text { tionnaire } \mathrm{N}=164\end{array}$ & $\begin{array}{l}\text { Gothenburg municipality } \\
\text { (kommun) } N=548,190\end{array}$ \\
\hline Education & $(n=109)$ & \\
\hline Post-high school education (> 3 years) & $\begin{array}{l}76 \% \text { Univ./Ph.D. } \\
6 \% \text { Prof. ed. }\end{array}$ & $34 \%$ \\
\hline \multicolumn{3}{|l|}{ Gross monthly household income (SEK)* } \\
\hline \multicolumn{3}{|c|}{ (Exchange rate $\approx 6.5 \mathrm{SEK} / \mathrm{USD}$ during the FOT) $(\mathrm{n}=163)$} \\
\hline 0-25,000 SEK & $9 \%(14)$ & 2014 median: 250,180 SEK \\
\hline $25,001-40,000$ SEK & $28 \%(46)$ & \\
\hline 40,001-55,000 SEK & $17 \%(27)$ & \\
\hline $55,001-70,000 \mathrm{SEK}$ & $20 \%(32)$ & \\
\hline More than 70,000 & $27 \%(44)$ & \\
\hline \multicolumn{3}{|l|}{ Mode split, all year } \\
\hline Car & & $\begin{array}{l}\text { Municipality } 40 \% \\
\text { City center } 24 \%\end{array}$ \\
\hline Public transport & & $\begin{array}{l}\text { Municipality } 27 \% \\
\text { City center } 31 \%\end{array}$ \\
\hline Cycling & & $\begin{array}{l}\text { Municipality } 8 \% \\
\text { City center } 8 \%\end{array}$ \\
\hline Walking & & $\begin{array}{l}\text { Municipality } 23 \% \\
\text { Center } 37 \%\end{array}$ \\
\hline
\end{tabular}

The demographic items indicated by a $*$ in the table are household-based, but the 164 ex-ante questionnaire responses from UbiGo participants do not represent 164 unique households. The number of households in Gothenburg at time of FOT: 250,716

demographics of Gothenburg, including residence, occupation and travel behavior.

\section{Data collection}

Data was collected via a mixed-methods approach, comprising questionnaires, personal or household interviews, focus groups, travel diaries, as well as use data, error reports and customer service issues. The basis for this paper is the questionnaire and interview data.

The participants were asked to fill out three online questionnaires: ex-ante, in-itinere, and ex-post (151 adults completed all three questionnaires). The ex-ante questionnaire concerned expectations, motivations to join and included a self-reported baseline for travel behavior. The in-itinere questionnaire addressed the participants' experience of all aspects of the service and included a measurement of current behavior; and the ex-post questionnaire concerned changes in behavior and willingness to continue with the service.

A selected number of participants were invited to ex-post interviews; 14 individual and three household interviews were performed. The interviews allowed the participants to elaborate around topics from the questionnaires; they were probed to provide more indepth information on the reasoning behind their opinions and to more thoroughly explain their experiences using the service. These audio-recorded interviews lasted 60-90 min. 


\section{Analysis}

Each interview was transcribed and summarized using a version of contact summary forms (Miles and Huberman 1994), in which statements regarding expectations, reasons, behavioral change, and reflections regarding travel and behavior were gathered. These summaries were comparatively analyzed and, from the pattern analysis, four subgroups of participants could be identified, as there were noteworthy differences between participants depending on their perception of the value the service would provide them combined with their expectations for behavioral change based on this service offer. The interview material was then revisited to explore behavior, reasoning, and reflections within these four categories to confirm the subgroups and identify underlying explanations.

The questionnaire data was first summarized for the entire group and subsequently analyzed based on the four identified subgroups. Statistical analyses of the questionnaire data were performed with the software SPSS.

\section{Results and analysis}

In the ex-post questionnaire, a majority (93\%) of the participants were satisfied with the UbiGo service, and $69 \%$ stated that they had become more satisfied with their traveling compared to before the trial. Overall the service appeared to have exceeded the expectations of participants: It has actually been beyond expectation, very smooth. The concept is really damned good. Seventy-nine percent said that they would like to continue as customers, while an additional $18 \%$ wanted to continue, but with preconditions related to economic aspects of the service and the reliability of the technology. At the end of the trial, many participants missed the service and the opportunities it provided: You notice now that you're not in it, that like...it feels kind of...it is a bother to travel in the normal way.

\section{Expectations of the service offer and behavioral changes}

From the ex-ante questionnaire, on the whole, participants joined mostly due to curiosity about the new concept and what it could offer them with $63 \%$ citing this as their main motivation, with convenience/flexibility, economy, and environment far behind (see Sochor et al. 2014). Some, but far from all, expected their mode choice and travel patterns to change during the trial (see Fig. 1a).

As mentioned, four different subgroups were identified based on the interview data. They were named Car shedders, Car accessors, Simplifiers, and Economizers based on the value that they perceived UbiGo would afford them. Table 2 describes these groups and their expectations of the service in-depth. The groups also differed sociodemographically, for example Economizers lived in a house (vs. an appartment) to a statistically significant greater extent than did all other subgroups, and they also had more adults per household and higher household income than did Car accessors. Degrees of car ownership and carsharing membership also differed. The subgroups also had different expectations of other types of change that would occur on the basis of the altered preconditions offered by the service (Fig. 1a). For example, the Car shedders expected 


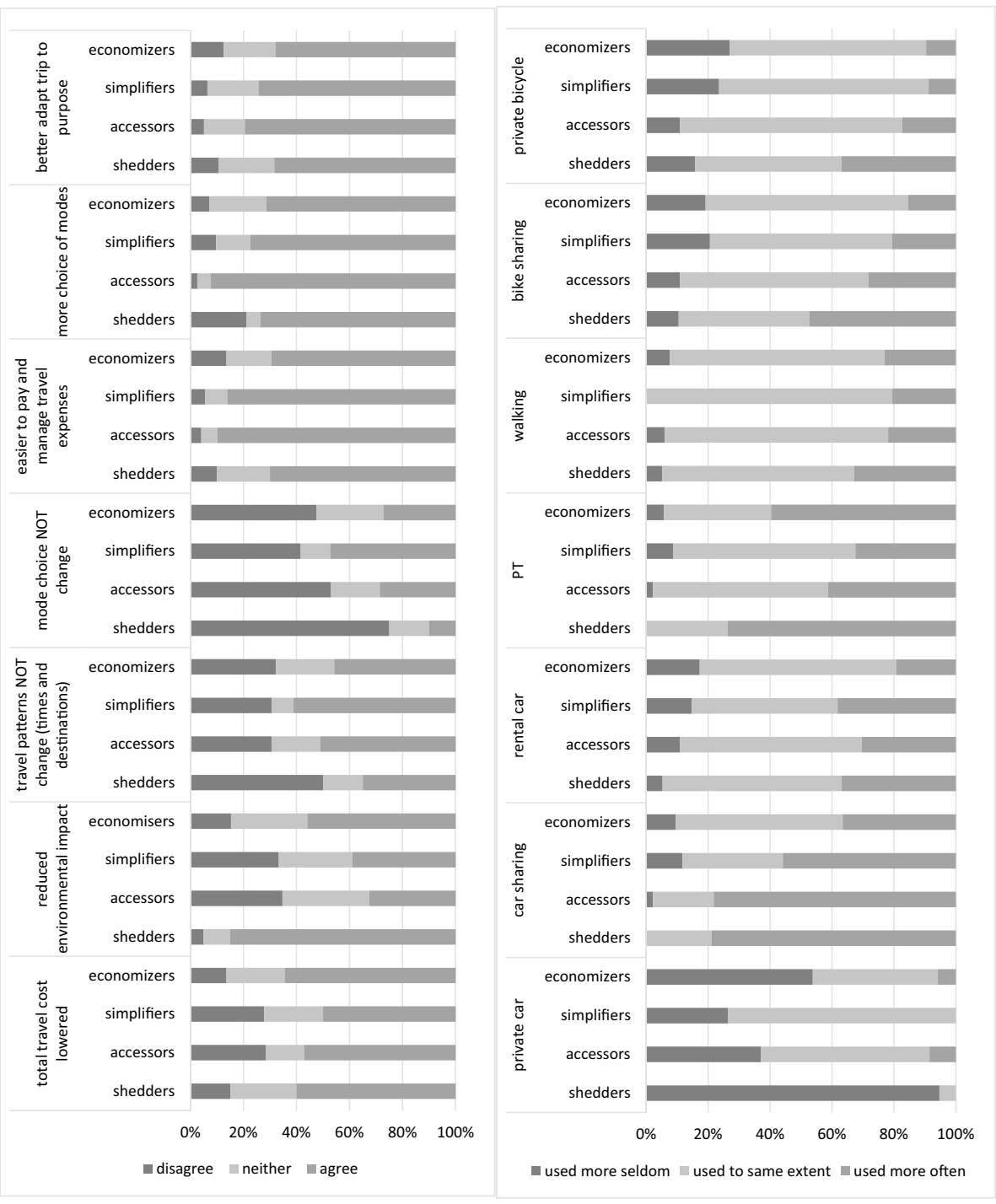

Fig. 1 a Expectations of changes (\% of each subgroup) from ex-ante questionnaire, left; and b Stated change in use frequency per mode (\% of each subgroup) from the in-itinere questionnaire, right

to reduce their environmental impact the most as they also expected their mode use to change the most (away from car). Accessors on the other hand looked forward to more choice of modes and thus being able to adapt the mode to the trip, as well as a simplified way of handling travel expenses (similar to the Simplifiers). 


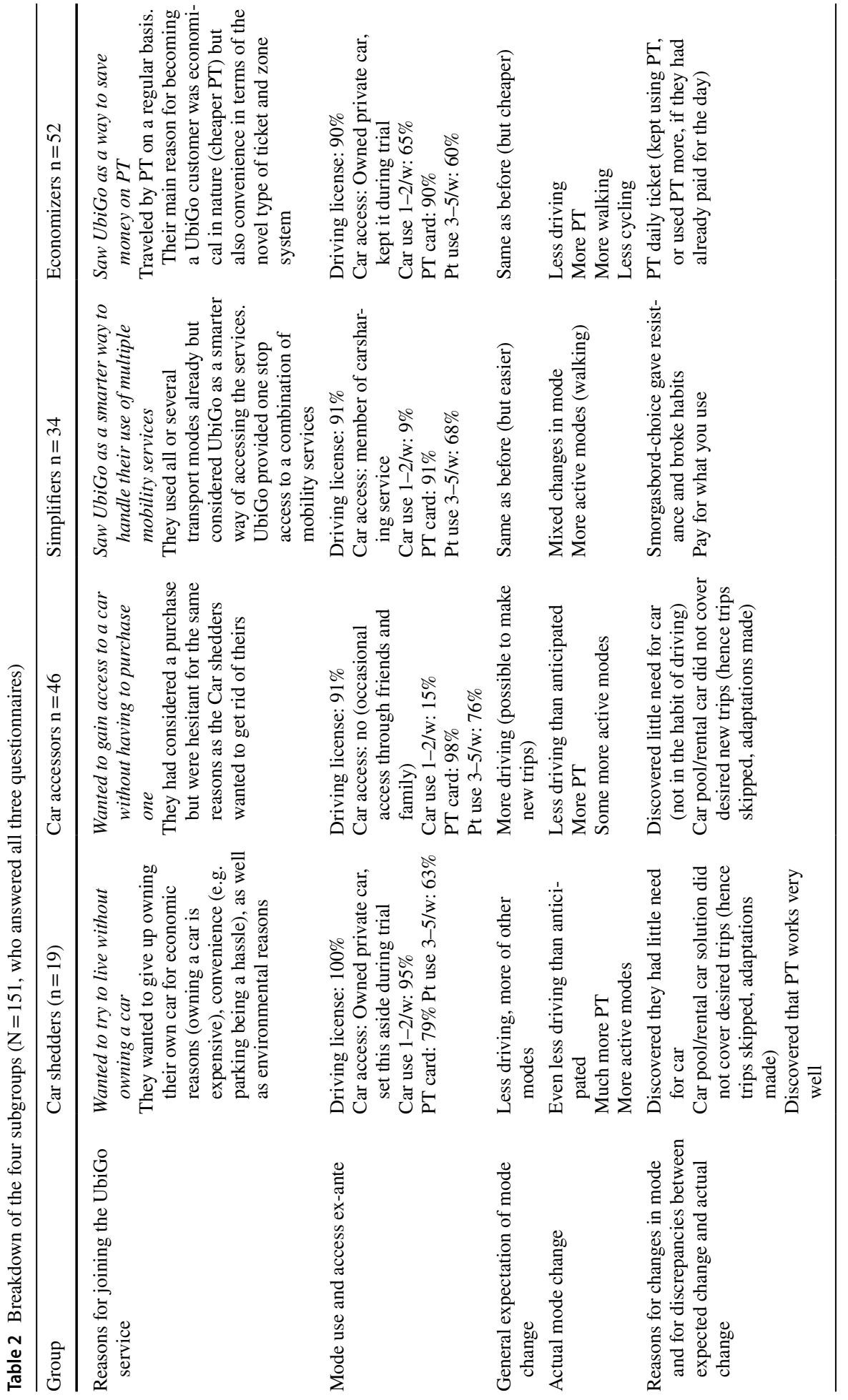




\section{Use of the service and changes in behavior}

At the end of the trial, the most frequently reported behavioral change was mode (42\%), followed by the amount of pre-trip planning (34\%), trip chaining (21\%), destinations (21\%), and travel time (21\%). There were also those, $36 \%$ of participants, who reported no change (mainly Simplifiers and Car accessors).

Looking closer at reported mode use changes, the overall trends are that all subgroups used car less and walked more. The two car-owning subgroups reduced their private car use; $95 \%$ of Car shedders and 53\% of Economizers reported using their car considerably more seldom than before the trial (see Fig. 1b). The Car shedders appear to have spread their former car trips across all other available modes, while the Economizers primarily used more PT (60\%), which may be due to their joining to get access to cheaper PT. They also used more carsharing and walked more, but less private bicycling. A large proportion of the Car accessors increased their use of carsharing (78\%) as well as rental cars $(30 \%)$ but reduced private car use (37\%), a result of not borrowing cars from friends and family anymore. At the same time many of them increased their use of PT (41\%), walking (18\%), bicycle-sharing (28\%), and private bicycle (17\%), even if some participants reported less use of these active modes. The fourth subgroup, Simplifiers, is the most split subgroup in the sense that they changed behavior but not in a uniform way; one share increased their use of most modes while another share decreased their use.

\section{(Mis)matches between expectations and changes}

Even if many of the changes described are in line with the participants' expected changes, the interviews showed that they did not fully match. The in-itinere questionnaire confirmed this; most participants did not experience a modal shift or travel pattern change to the degree expected. For some this meant changing more than expected, and for others it meant changing less (see summary Table 2). Some reinforced their existing behaviors but in ways they did not envisage, depending on their ex-ante goals. The two main identified mismatches are lower than expected car use, and higher than expected PT and active mode use.

\section{Lower than expected car use}

The discrepancy between expected and actual change is especially noticeable concerning car use. Car shedders, who used their car regularly before the FOT, reduced their car use well beyond their expectations: We had heaps of car credits left. I approximated for a greater need that wasn't there in the end. We had already reduced car driving to a minimum, or so we thought...So yes, I knew we would change our travel behavior but not to this extreme. One reason was that the car was not sitting outside, ready and waiting, as usual: You notice if the car is sitting out there [in the parking lot], then travel behavior changes, it does. By not having private car access, participants felt they could escape the lock-in effects it created: You get pretty comfortable when you have a car. Not having one gives you different opportunities ... moving your body a bit more and so, bicycling, walking, and public transport too, for that matter. Another explanation was that this subgroup came to realize how well the PT system actually worked and they discovered that it covered trips for which they initially believed they needed a car. 
Before the FOT, Car accessors imagined they would be using carsharing for various new types of trips. Some imagined practical trips: Now that we had UbiGo we thought 'well, let's go grocery shopping with the Sunfleet-car' but we never did actually, while others planned more social trips: We thought we would take the car out to our parents' houses for Sunday dinner and such, but that didn't happen. As the participants did not make those imagined trips, they did not use cars as much as expected. The participants' reason for not making these trips were that they were not in the habit of making them with a car, that they did not have time, or that the trips were not part of the plan: Maybe the reason is that you already have an established way of planning; that you plan everyday life. It maybe says a lot about that you're not as car dependent as you think. Others discovered that car was not the best option which they had initially thought ... and then we have done a lot of things where we didn't even need the car. It has been unnecessary since [PT] has been just as easy. The car costs a bit more and has higher environmental impact so then you use public transport anyway. Still, they appreciated the access they gained: I haven't really used carsharing at all, really, but it was still nice to know that it was available.

For both these subgroups, a further reason for low car use was that using UbiGo required more planning. One of the car-owning households explained: Car driving has gone down because we have planned more.-Yes, you coordinate more and merge trips... sometimes you don't go, while another participant said: We have made fewer spontaneous trips without any direct purpose, other than to see if maybe you could find something in a store. Also, the non-car owners had planned more: You gathered the trips to one occasion, instead of going impromptu like you do with a car. These comments explain part of the reduction in car use but also the increase in trip chaining. However, the participants did not consider this increased planning as something negative; it was more considered as a matter of fact. The advantage of not making unnecessary errands by car as well as feeling in control of their travel behavior outweighed the effort of planning.

Additionally, the participants found more ways of reducing their need for a car by adopting other behaviors such as meeting friends downtown instead of driving to their house for dinner, shopping in the local grocery store instead of driving to the large supermarket or finding a completely new way of dealing with grocery shopping: We found other alternatives for that too, we started with mat.se [online grocery shop] and got it delivered.

The participants also discovered that neither carsharing nor rental cars fit the types of trips for which they wanted to use a car. These trips often included going to a more or less remote location, sometimes with plenty of baggage, and then staying in that location for some hours before going back again. Examples were golfing, horseback riding, or going to the beach: I need [the car] only in the morning, but then it will just sit there for $8 \mathrm{~h}$ with the costing more and more every hour. Like, it is not going to work, so that stopped me. For such day trips, there is a gap in the pricing models where carsharing is suitable for short, hour-long errand trips in the city, and rental cars are suitable for longer trips, such as over the weekend to another town.

In sum, the level of car use was lower than expected. The reasons were that the participants did not find any real need for a car. Instead they found that there were well-functioning alternatives or that expected activities did not take place. Also, the collective car services did not provide the right conditions for each and every type of desired trip. Overall, this meant that more planning and adaptation of activities became necessary but were not unwelcomed. 


\section{Higher than expected use of active modes and public transport}

An increase in PT use as well as in the use of more active modes can be observed in all subgroups. While this was expected from the Car shedders, several Economizers and Simplifiers changed their behavior despite not expecting to. The unexpected changes can be connected to certain features of the design and setup of the UbiGo service.

One important feature of the UbiGo service was that it allowed users to pay only for the services used. The participants found this model more favorable than how they usually paid for their travel, primarily with PT: It doesn't cost any money if you don't use public transport one day, which is a big difference from a monthly pass of course. It matters if you are at home for 3 days and get to pay for those days anyhow. Here, you actually only pay for what you use. The feature triggered deliberations and a change in behavior. As you do not pay 'in vain' for the car in the parking space, or do not 'lose' a day of your monthly PT pass, you become more free to choose the appropriate transport mode for the trip at hand. In some cases, this led to the choice of an active mode: I don't take the tram just to take the tram, instead I think, should I use the bicycle instead? It is a minor thing, but it makes you think in another way.

Paying for what they used also initiated economic considerations in relation to the trip at hand. The participants reflected upon how they could best adapt to the system to avoid paying in vain. Again, this led to an increased use of active modes like cycling or walking: With UbiGo I think ... 'Now, the whole day has almost passed and I haven't used my daily ticket, should I activate it now? No, I'll walk'.

The higher than expected use of PT specifically can most probably be attributed to the PT daily ticket, unique to the UbiGo offer. This was very popular among the participants as it simplified the use of PT and in some cases also reduced the cost. UbiGo's daily ticket cost approximately the same as a regular, one-way, single ticket, even if the price of the ticket was based on what one day of a monthly pass would cost. The daily ticket simplified things in that one did not have to keep track of how many minutes it was valid, choosing zones was made much easier, and one did not have to tap in and out.

It has already been mentioned that several participants had hesitated to buy a daily ticket if they could go by active mode instead, but at the same time the daily ticket prompted an increased use of PT for some shorter trips in the city: It was easy and pretty cheap to go by tram, which made me opt out of bicycling to a higher degree than I would have otherwise. However, for most participants this was only true when the participant had already paid for the day: I think maybe that when you already have started using public transport one day, you take the opportunity to use it a bit more.

Another feature of importance is that UbiGo offered easy access to a perceived wider range of options. Participants experienced that they had a freedom to choose in the first place, more to choose amongst, and also found it easy to utilize the options: Simply going to town has become more convenient; if there isn't a tram in seven minutes I'll take a bicycle instead; it's more flexible. At the same time, having the full range of options ready at hand required the participants to reflect on which mode was more suitable for the upcoming trip: Having this smorgasbord of different transport modes allowed you to question or think about which mode you would use. Especially participants belonging to the Simplifiers mentioned this moment of reflection as a cause for their unexpected behavioral changes. Here, the app's start screen, listing the modes, played an important role: Well you use [public transport] the most, but every time you want to use it, you come into contact with the project and log-in there and then you see the modes and such. At that point, a small thought 
appears around it. This list, presenting all alternatives in one place with equal 'weight', appeared to enforce the idea that one had to make a choice every time. One was made to go through the list and assess the suitability of each mode in relation to one's needs for that day. This led participants to consider alternatives that they otherwise would have disregarded, and they sometimes concluded that the best mode was one not in the list: walking. It also increased participants' planning and their reflection on their general travel behavior. A few participants expressed negative sentiments towards having to plan and reflect more, but most were satisfied with the extra push to reflect on their travel behavior: It's not about being a bus person or a walking person; you are everything. And it's about using reasonable proportions of each. To be able to see 'when do I need this and when do I need that?'. That was very important. This is exactly it; how do you change people's behavior? And this was just the right level of resistance for me to see 'which mode is good for me today?'.

In sum, the design of the service made the participants more prone to consider all available modes, including walking and cycling, especially for the first trip of the day which led to an increase in active modes. The app played a mediating role. However, if they had already chosen to activate the daily ticket for PT, they were more prone to choose PT for the rest of the day's trips for economic reasons.

\section{Discussion and implications}

\section{The customer and the value offering}

The UbiGo customers/participants were not chosen at random; no randomized allocation to different groups was undertaken, and no control group was created. The choice was instead strategic; the target group was travelers who (apart from stating an interest in participating) were considered to potentially benefit from the service, i.e. for whom the service could provide an added value or relative benefit. This is essential from both the innovation dissemination and commercial perspectives, as users' adoption of an innovation relies on it offering a perceived relative benefit compared to the existing solution (product and/or behavior) (Rogers 1995); and the relative benefit will depend on the value offering, which is related to the MaaS level (Sochor et al. 2017). In the case of UbiGo, MaaS level 3, this meant targeting urban households with reasonable distances to PT and carsharing, and a service design that offered perceived added value (see below). The approach can thus be compared with a market segmentation into different customer groups with the purpose of creating, in this case, a service that could meet their specific needs rather than a solution that would 'fit all'. According to Anable and colleagues (2006), there is a general consensus in literature that a "...staged and targeted strategy of travel behavior change" is likely to be more effective, but the most common segmentations appear to be based on behavior, i.e. car-users and PT users, or on attitudes (cf. Anable 2005), in order to deliver targeted information rather than on actual, contextualized transport need in order to design a product adapted to this need.

A comparison between the demographics of Gothenburg municipality and the subscribers of UbiGo show some important differences that must be considered in assessing the potential of MaaS (Karlsson et al. 2017). For instance, UbiGo was more attractive for those living in the city centre than those living in suburban areas (49\% compared to $23 \%$ when considering all Gothenburg citizens), the share of retired subscribers was very low compared to Gothenburg overall (1\%) and the share of students slightly lower than the 
municipality (11\% compared to 15\%). In addition, the distribution of participants across different location areas (i.e. city centre, southwest, southeast, northeast, and north) differed from the municipality but mirror fairly well access to carsharing facilities.

The FOT participants' evaluation shows that the UbiGo service was considered to solve their transport need and that participants were more satisfied with the transport system using the service. This illustrates the potential of MaaS, but there are other important design elements, deeper than the general MaaS concept of 'bundling' or having everything in 'one spot' (e.g. a marketplace à la MaaS levels 1 and 2) that are important to customers and that influence behavior (Sochor et al. 2016). For example, the way in which one pays (e.g. increasing or decreasing lock-in effects), the perceived freedom to choose, and the way the service presents potential choices are very important if users are to feel both satisfied with the service and make sustainable choices. Other crucial elements relate to how well the service both practically and psychologically supports the (potential) change process (Strömberg et al. 2016), as people are not well aware of their travel needs and behaviors going into a new type of service like MaaS and therefore have difficulties anticipating potential changes (further discussed below). Open evaluations of additional MaaS implementations need to be performed to further understand the relationships between design elements (and business models) of successful value offerings, customer satisfaction, and sustainability impacts as related to different types of MaaS (e.g. levels 0-4 Sochor et al. 2017).

\section{What led to the behavior changes?}

UbiGo intended to support more sustainable urban mobility without privately owned cars. However, a distinctive characteristic of the service was meeting the household's full mobility needs-even if this included car use. Although estimates suggest that there are viable options for $40 \%$ of car journeys, and with small investments an additional $40 \%$ (Brög and John 2001, in Chapman 2007) some trips may be impossible to accomplish, or only with considerable effort, without a car. Certain trips were also difficult within the UbiGo model, which could be an issue potentially affecting acceptance of such a service in the long run (Sochor et al. 2015). Earlier studies have shown that the investment in a private car can be determined by the perceived need shaped by very infrequent, out of the ordinary trips. The participants in the trial had therefore the opportunity to choose a car-if and when it was considered most useful. This flexibility enabled participants to choose the mode most suitable to the trip at hand, instead of being locked into a specific mode. This may appear strange as the service did not actually offer any new modes but several participants mentioned how certain lock-in effects had stopped them from choosing among available modes. Owning a car costs a considerable amount of money even if one does not use it and therefore one might as well use it; a PT pass creates similar effects. UbiGo offered instead an integrated multimodal service where one paid for what one used, which further enhanced the flexibility of the service. Nevertheless, some lock-in effects could be observed during the FOT, as participants tended to use PT more if they had already paid for the day and less if they had not. However, in UbiGo, the lock-in effects were short-term (i.e. a trip or a day) rather than long-term (month, year, or longer); a step forward.

Another key feature was the design of the app, which appears to have played an important, intervening role in the participants' travel behavior, not only because it was the 'interface' by which trips were accessed, but as it presented different modes as equally feasible 
options every time a trip was to be undertaken. This list of options made participants reflect on mode choice, hereby acting as a kind of habit intervenor, and over time made them more conscious of the 'smorgasbord' of transport choices. The possibility to choose different modes, in combination with the app, can thus be argued to have contributed to a change in participants' perception of what was feasible, i.e. a change in perceived action space (cf. Strömberg 2015). Having a continuous, built-in reminder of the available options may have different, habit-breaking effects than one-time eye-openers that characterize information campaigns.

Despite the encouraging results from UbiGo, it is difficult to draw any general conclusions regarding how many people will change behavior due to a service of this type and how big the changes will be. The findings show that behavioral changes vary with the household's initial preconditions and motivations/reasons. The findings also show that the participants were unaware of their preconditions, travel needs, and behavior when joining the service, and thereby could not predict how their behavior would change. In adopting the service, participants spent much time figuring out those preconditions and needs. The flexibility of the service played an important role in supporting this change process, as it showed the options and allowed participants to alter their subscription when they had figured out that their initial assumptions about their own travel behavior were incorrect. The behavior change process observed in the study needs to be further explored to be able to model demand and design effective MaaS but indicates both that such services need to contain flexibility to allow people to change within the service, and that the service should support people in their exploration of their own preconditions, and thus which new behaviors they can adopt (Strömberg et al. 2016).

\section{Context}

Although the design of the service is argued as fundamental to support the reported behavioral changes, the social and technological context in which the service was introduced must also be acknowledged. The UbiGo service was, as already mentioned, based on existing transport services and infrastructures, and thus potential customers were those deemed to have sufficient access to the existing services and infrastructures. Although the UbiGo service 'only' repackaged already available services, the process utilized: (1) the dissemination of new mobile technology, i.e. smartphones, even though access differs across age groups; and (2) shifting consumer attitudes and behaviors towards sharing and servicing with less emphasis on personal ownership (Hamari et al. 2016).

Just as there is currently no definitive version of 'MaaS', there also does not exist any 'one size fits all' MaaS for all contexts. Noting that MaaS is largely an organizational approach, any MaaS service needs to be tailored to the local geography, culture, and stakeholder ecosystem, as well as personalized to the individual/household. The tailoring of the service should also be coupled with a cost-effectiveness analysis for the case at hand.

\section{Final thoughts}

The case of UbiGo illustrates the potential for an, overall, 'virtuous cycle' between the service and its impact (e.g. behavioral change, sustainability). The need-based approach for the entire household and design elements such as the 'transportation smorgasbord', simplicity, improved access and flexibility, economy, and trialability (Sochor et al. 2016) facilitated the use of the service in a personalized way. It met participants' 
mobility needs (almost; see below) by offering a full range of choices in a flexible manner. The pricing structure encouraged mode choice for each trip and reduced lock-in effects, and the app design made the choices apparent, which enabled the customer to freely choose and experiment within their adaptable, personalized subscription. This led to both anticipated and unanticipated behavioral changes, which meant that participants both gained insight into that they did not previously fully understand their needs and preconditions, and re-evaluated their choices, options, and perceptions of convenience. And in the end, users generally shifted to more sustainable transport choices.

Overall, the results from the trial demonstrate the potential and relevance of new and innovative measures such as 'Mobility as a Service' solutions. Although it does not yet exist, the larger vision is to achieve MaaS level 4 in which local policies are integrated into the service, whereby MaaS becomes more strongly connected to city governance and planning (Sochor et al. 2017). In the end, fundamentally new, different and targeted transport service offers are needed, based on a more holistic approach and the notion of a co-operative and interconnected transport system (including services, infrastructure, information, payment, etc.), where boundaries between not only transport modes are blurred but also between public and private actors.

Author contributions H. Strömberg: Study planning, Data collection and Analysis, Manuscript writing and Editing. I. C. M. Karlsson: Study planning, Manuscript writing. J. Sochor: Study planning, Data collection and Analysis, Manuscript writing.

\section{Compliance with ethical standards}

Conflict of interest On behalf of all authors, the corresponding author states that there is no conflict of interest.

Open Access This article is distributed under the terms of the Creative Commons Attribution 4.0 International License (http://creativecommons.org/licenses/by/4.0/), which permits unrestricted use, distribution, and reproduction in any medium, provided you give appropriate credit to the original author(s) and the source, provide a link to the Creative Commons license, and indicate if changes were made.

\section{References}

Anable, J.: 'Complacent Car Addicts' or 'Aspiring Environmentalists'? Identifying travel behaviour segments using attitude theory. Transp. Policy 12(1), 65-78 (2005). https://doi.org/10.1016/j.tranp ol.2004.11.004

Anable, J., Lane, B., Kelay, T.: An evidence base review of public attitudes to climate change and transport behaviour. Department for Transport, London (2006)

Audenhove, F.-J.V., Korniichuk, O., Dauby, L., Pourbaix, J.: The future of urban mobility 2.0: imperatives to shape extended mobility ecosystems of tomorrow. In: Lab, A.D.L.F. (ed.) (2014)

Börjesson, M., Eliasson, J., Hugosson, M.B., Brundell-Freij, K.: The Stockholm congestion charges - 5 years on. Effects, acceptability and lessons learnt. Transp. Policy 20, 1-12 (2012)

Brög, W.: Individualized marketing: implications for transportation demand management. Transp. Res. Rec. J. Transp. Res. Board 1618, 116-121 (1998)

Brög, W., John, G.: Personalised marketing-the Perth success story. In: Proceedings: Marketing Public Transport Conference, Auckland, New Zealand (2001)

Cairns, S., Sloman, L., Newson, C., Anable, J., Kirkbride, A., Goodwin, P.: Smarter choices: Assessing the potential to achieve traffic reduction using 'Soft Measures'. Transp Rev 28(5), 593-618 (2008). https://doi.org/10.1080/01441640801892504

Chapman, L.: Transport and climate change: a review. J. Transp. Geogr. 15(5), 354-367 (2007). https:// doi.org/10.1016/j.jtrangeo.2006.11.008 
Graham-Rowe, E., Skippon, S., Gardner, B., Abraham, C.: Can we reduce car use and if so, how? A review of available evidence. Transp. Res. Part A: Policy Pract. 45(5), 401-418 (2011). https://doi. org/10.1016/j.tra.2011.02.001

Hamari, J., Sjöklint, M., Ukkonen, A.: The sharing economy: Why people participate in collaborative consumption. J. Assoc. Inf. Sci. Technol. 67(9), 2047-2059 (2016). https://doi.org/10.1002/asi.23552

Kamargianni, M., Li, W., Matyas, M.: A comprehensive review of "Mobility as a Service" systems. In: Transportation Research Board 95th Annual Meeting 2016, vol. 16-5401, (2016)

Karlsson, M., Sochor, J., Aapaoja, A., Eckhardt, J., König, D.: Deliverable 4: impact assessment of MaaS. (2017)

König, D., Sochor, J., Eckhardt, J., Böhm, M.: State-of-the-art survey on stakeholders' expectations for Mobility-as-a-Service (MaaS). In: 23rd World Congress on Intelligent Transport Systems, ITS Australia (2016)

Lyons, G.: Technology fix versus behaviour change. In: Grieco, M., Urry, J. (eds.) Mobilities: new perspectives on transport and society, pp. 159-177. Ashgate, Farnham (2011)

Marsden, G., Mullen, C., Bache, I., Bartle, I., Flinders, M.: Carbon reduction and travel behaviour: Discourses, disputes and contradictions in governance. Transp. Policy 35, 71-78 (2014). https://doi. org/10.1016/j.tranpol.2014.05.012

May, A.D.: Urban transport and sustainability: The key challenges. Int. J. Sustain. Transp. 7(3), 170-185 (2013). https://doi.org/10.1080/15568318.2013.710136

Miles, M.B., Huberman, A.M.: Qualitative data analysis: An expanded sourcebook. Sage, Thousand Oaks (1994)

Preston, J.: Integration for seamless transport. In: International Transport Forum Discussion Papers 2012/01, OECD Publishing, Paris (2012). http://dx.doi.org/10.1787/5k8zvv81mswl-en

Rogers, E.: Diffusion of innovation, 4th edn. The Free Press, New York (1995)

Sochor, J., Arby, H., Karlsson, M., Sarasini, S.: A topological approach to Mobility as a Service: a proposed tool for understanding requirements and effects, and for aiding the integration of societal goals. In: 1st International Conference on Mobility as a Service (ICOMaaS), Tampere, Finland (2017)

Sochor, J., Karlsson, I.M., Strömberg, H.: Trying out mobility as a service: Experiences from a field trial and implications for understanding demand. Transp. Res. Rec. J. Transp. Res. Board 2542, 57-64 (2016)

Sochor, J., Strömberg, H., Karlsson, I.C.M.: Travelers' motives for adopting a new, innovative travel service: insights from the UbiGo field operational test in Gothenburg, Sweden. In: Paper Presented at the 21st World Congress on Intelligent Transportation Systems, Detroit, MI (2014)

Sochor, J., Strömberg, H., Karlsson, I.C.M.: Implementing Mobility as a Service: challenges in integrating user, commercial, and societal perspectives. Transp. Res. Rec. J. Transp. Res. Board 4(2536), 1-9 (2015). https://doi.org/10.3141/2536-01

Strömberg, H.: Creating space for action-supporting behaviour change by making sustainable transport opportunities available in the world and in the mind. Chalmers University of Technology, Gothenburg (2015)

Strömberg, H., Rexfelt, O., Karlsson, I.C.M., Sochor, J.: Trying on change-Trialability as a change moderator for sustainable travel behaviour. Travel Behav. Soc. 4, 60-68 (2016). https://doi.org/10.1016/j. tbs.2016.01.002

Helena Strömberg is a Senior Lecturer at Division Design \& Human Factors at Chalmers University of Technology, and holds a Ph.D. in Human-Technology-Design. Her research focuses on how people adopt new sustainable behaviour and new sustainable products and services into their everyday lives, mainly within the transport domain.

I. C. MariAnne Karlsson is professor (chair) in Human-Technology Systems at Chalmers University of Technology. She has in a series of projects investigated barriers and enablers to the development and dissemination of MaaS (Mobility-as-a-Service) as well as the impact of MaaS on users travel behaviour.

Jana Sochor holds a Ph.D. in Transport Science from KTH-Royal Institute of Technology. She is a Senior Researcher at RISE Viktoria and Chalmers University of Technology. She has served as a Main Member of the Emerging and Innovative Public Transport and Technologies Committee of the Transportation Research Board since 2016. Her research focuses on understanding end users' perceptions, motives, and behaviors as related to MaaS so as to improve service/system design and development, adoption, and effect, as well as positively impact users' mobility choices in a more sustainable manner. 